\title{
Cooperative Behaviors in Group-Living Spider Mites
}

\author{
Peter Schausberger ${ }^{1 *}$, Shuichi Yano ${ }^{2}$ and Yukie Sato ${ }^{3}$ \\ ${ }^{1}$ Department of Behavioral and Cognitive Biology, University of Vienna, Vienna, Austria, ${ }^{2}$ Laboratory of Ecological \\ Information, Graduate School of Agriculture, Kyoto University, Kyoto, Japan, ${ }^{3}$ Mountain Science Center, University \\ of Tsukuba, Tsukuba, Japan
}

Cooperative behaviors are evolutionary stable if the direct and/or indirect fitness benefits exceed the costs of helping. Here we discuss cooperation and behaviors akin to cooperation in subsocial group-living species of two genera of herbivorous spider mites (Tetranychidae), i.e., the largely polyphagous Tetranychus spp. and the nest-building Stigmaeopsis spp., which are specialized on grasses, such as bamboo. These spider mites are distributed in patches on various spatial scales, that is, within and among leaves of individual host plants and among individual hosts of single or multiple plant species. Group-living of spider mites is brought about by plant-colonizing foundresses ovipositing at local feeding sites and natal site fidelity, and by multiple individuals aggregating in the same site in response to direct and/or indirect cues, many of

OPEN ACCESS

Edited by:

Miriam H. Richards, Brock University, Canada

Reviewed by:

Jutta M. Schneider, University of Hamburg, Germany Yael D. Lubin, Ben-Gurion University of the Negev, Israel

${ }^{*}$ Correspondence:

Peter Schausberger peter.schausberger@univie.ac.at

Specialty section: This article was submitted to Social Evolution,

a section of the journal Frontiers in Ecology and Evolution

Received: 21 July 2021 Accepted: 04 October 2021 Published: 30 November 2021

Citation:

Schausberger $P$, Yano $S$ and Sato Y (2021) Cooperative Behaviors

in Group-Living Spider Mites.

Front. Ecol. Evol. 9:745036. doi: 10.3389/fevo.2021.745036 which are associated with webbing. In the case of the former, emerging patches are often composed of genetically closely related individuals, while in the case of the latter, local patches may consist of kin of various degrees and/or non-kin and even heterospecific spider mites. We describe and discuss ultimate and proximate aspects of cooperation by spider mites in host plant colonization and exploitation, dispersal, anti-predator behavior, and nesting-associated behaviors and conclude with theoretical and practical considerations of future research on cooperation in these highly rewarding model animals.

Keywords: byproducts, direct fitness, indirect fitness, kin, kin selection, non-kin, spider mites, Tetranychidae

\section{BACKGROUND}

Cooperative behaviors abound in animals but pose a challenge for evolutionary theory because of direct fitness costs to actors (helpers). Cooperative behaviors are likely to evolve whenever animals live together and interact for extended periods of time, and have been mainly examined in vertebrates and eusocial insects, and, here, especially among kin. In contrast, our insights into the occurrence and evolution of cooperation in non-eusocial group-living arthropods, and among nonkin and mixed kin and non-kin, are limited. Here, we give an account of various types of cooperative behaviors in group-living plant-inhabiting spider mites (Figure 1). These animals have been rarely subjected to research targeting cooperation but show various behaviors that clearly qualify as cooperation or suggest cooperation. We start with a theoretical delineation of cooperation, then introduce the biological and ecological features of spider mites that render them ideal animals to view certain behaviors from the perspective of cooperation and move on to report and discuss proximate and ultimate aspects of cooperation and cooperation-like behaviors of spider mites in 
selected behavioral-ecological contexts. The examples described are not meant to be exhaustive but to illustrate the diversity and ubiquity of cooperative behaviors in spider mites. We conclude our perspective article by highlighting the key features of cooperation in spider mites and point at opportunities and caveats in future research on this very topic and animals.

\section{The Idea of Cooperation}

Cooperation is defined as any behavior that has evolved, at least in part, to enhance the fitness of other individuals (e.g., West et al., 2007; Gardner et al., 2009). The fitness-enhancing (helping) individual is called the actor, and the fitness-enhanced (helped) individual is called the recipient. Actors incur some fitness cost, either directly because of temporary reduction of their individual fitness or indirectly because of increasing the fitness of others (fitness is a relative indicator; thus, if the fitness of recipients is enhanced, individual fitness of the actor is reduced, in relative comparison). As predicted by pertinent theories, such as kin selection (Hamilton, 1964) and reciprocity (Trivers, 1971), cooperation is only evolutionary stable if the actor is more than compensated for the costs of helping and obtains a direct fitness benefit via the enhancement of its individual fitness, and/or an indirect fitness benefit via the enhanced fitness of recipients sharing genes with the actor (Sachs et al., 2004; West et al., 2007; Gardner et al., 2009). These two mutually non-exclusive ultimate drivers of cooperative behavior may be proximately subdivided according to the mode of cooperation and route of fitness gain, with authors differing in the terminology of subtypes yet often having similar, strongly overlapping, or identical meanings. Direct fitness benefits, which are based on shared interests in cooperation, may arise from byproducts of otherwise selfish behaviors of the actor, and/or enforced cooperation, that is, rewarding cooperation and punishing non-cooperation (Gardner et al., 2009; originally dubbed reciprocal altruism by Trivers, 1971; similar to directed reciprocation sensu Sachs et al., 2004). Indirect fitness benefits may arise from population viscosity (i.e., limited dispersal passively leading to actors locally interacting more likely with kin than non-kin recipients; Hamilton, 1964) and/or kin discrimination (i.e., helping actors recognizing and preferentially interacting with kin recipients) and/or green beard effects (i.e., helping actors recognizing genetically predetermined cooperation intents of helped recipients, no matter of their relatedness at other genetic loci) (e.g., Sachs et al., 2004; Gardner et al., 2009). Sachs et al. (2004) used the terms kin fidelity for site-specific helping kin, that is, in a given site, kin are more likely to encounter each other than non-kin, without the need of kin recognition (this also includes population viscosity), and kin choice for active kin discrimination. Further, these authors subdivided byproducts into one-way, which are behaviors that are not necessarily selected for cooperation, two-way, i.e., fitnessenhancing behaviors when performed in a group and include synergism (sensu Queller, 2011), and byproduct reciprocity. Queller (2011) extended inclusive fitness theory (Hamilton, 1964) to describe how cooperation may evolve between kin, kith (selection of neighbors who are neither kin nor kind via manipulation, actor-recipient choice, or actor-recipient fidelity feedback), and kind (based on green beard alleles).

\section{Spider Mites as Cooperators}

Here, we give an overview of cooperation and behaviors akin to cooperation by true spider mites (Tetranychidae), which clearly represent cooperative behaviors or which could qualify as cooperative behaviors yet we do not have enough information to judge whether these behaviors indeed qualify as cooperation according to the definitions described above. Spider mites (Tetranychidae) are globally distributed, mostly group-living herbivores (Helle and Sabelis, 1985 for review; Figure 1). Spider mites are highly rewarding model animals to view specific kin, non-kin, and heterospecific interactions from an evolutionarygrounded cooperation perspective, for a number of biological and ecological features. (i) As their name suggests, spider mites possess spinning glands in their mouthparts, with basic spinning types, such as Tetranychus spp., always and consistently spinning threads while walking (by every mobile life stage), and advanced types, such as some bamboo spider mites, being able to switch thread production on and off (Hazan et al., 1974; Saito, 1983; Clotuche et al., 2012). Over time, spinning threads result in three-dimensional webs on leaves and other plant parts, on, and under, which spider mites cohabit. The sophistication and complexity of jointly produced webs differ among spider mite genera and species, with the most advanced types being rooflike nests with protected entrances observed in grass spider mites Stigmaeopsis spp. (Saito, 1983). Accordingly, many cooperative behaviors of true spider mites and behaviors akin to cooperation are characterized and mediated by the joint use of webs produced by individual mites. Webs and single spinning threads are also beneficial as railroads and used for communication (Saito, 1983 for an overview). The ability to produce spinning threads is a decisive feature for the evolution of cooperative behaviors by spider mites. (ii) Most spider mite species are patchily distributed on their host plants and live in groups, with webbing being an important aspect of group formation and cohesion. (iii) The vast majority of spider mite species are arrhenotokous, that is, females produce haploid sons from unfertilized eggs and diploid daughters from fertilized eggs (Saito, 2010). Due to arrhenotoky, son-mother and, following mother-son mating, son/brother-sister coefficients of relatedness are 1, which has important implications to founder effects. (iv) Arrhenotoky allows colonizing host plants and the founding of patches/groups also by single immature or adult unfertilized females. While young mated females are the predominant dispersing life stage (Margolies and Kennedy, 1985; Li and Margolies, 1993; Azandémè-Hounmalon et al., 2014), also immatures, males and unfertilized females disperse (Brandenburg and Kennedy, 1982; Krainacker and Carey, 1990). For indirect fitness benefits selecting for cooperative behaviors of spider mites, the host plant colonization patterns seem as important as population viscosity in determining the kin structure within local patches and, in consequence, at regional levels. Due to arrhenotoky, any local patch founded by single females will, at least initially, result in high intra-group relatedness because of the possibility of motherson and brother-sister mating. Patches founded by several females, or when other individuals later arrive on the host plant, may be composed of only kin if later arrivers come from the same source. Alternatively, they may represent mixed kin/non-kin 

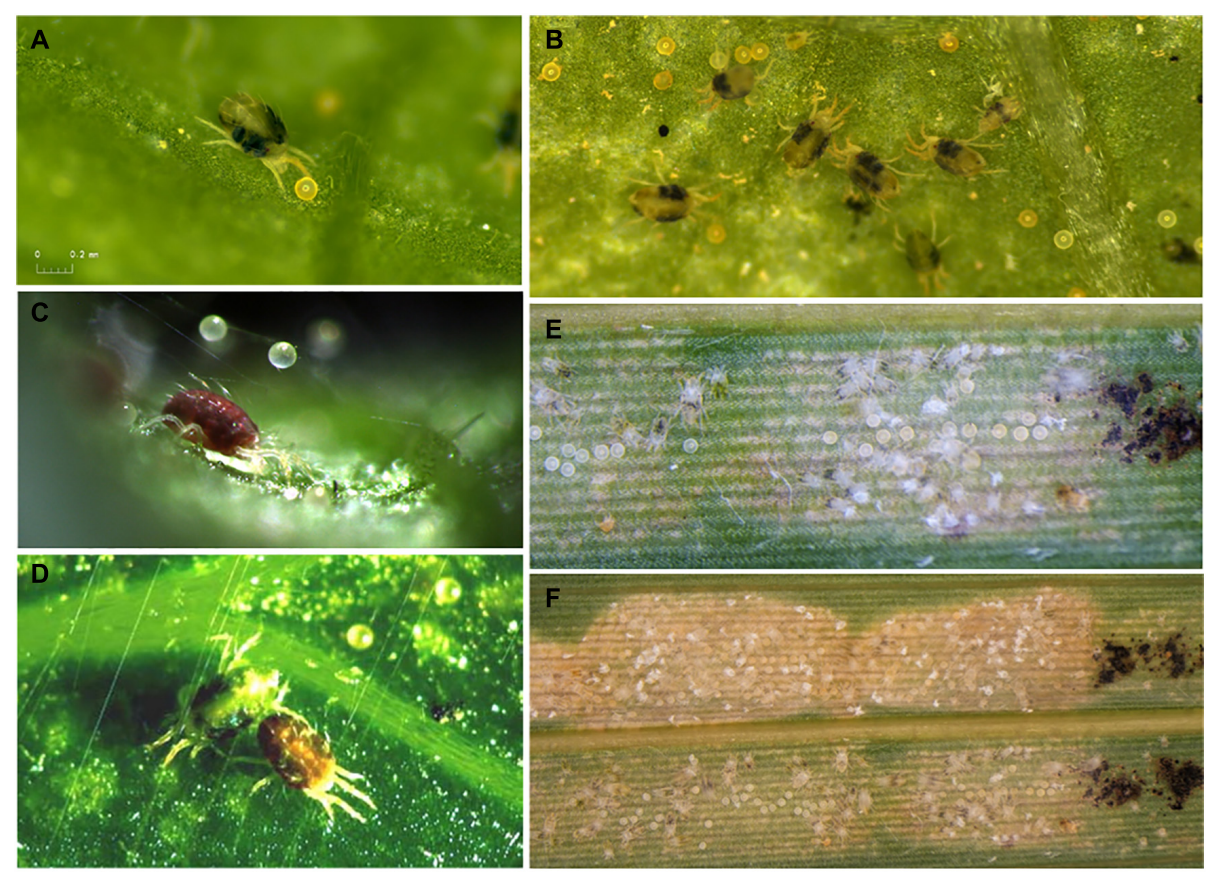

FIGURE 1 | (A) Tetranychus urticae female with egg, (B) group of T. urticae females and their offspring, (C) Tetranychus kanzawai female beneath spinning threads and eggs attached to threads, (D) T. urticae and T. kanzawai females sharing web, (E,F) nests of Stigmaeopsis longus on bamboo leaves, with all life stages and exuviae inside the nest and fecal piles outside the nest close to the entrance; the haze in (E,F) is caused by the woven roof of the nests; (C) (A,B) by PS, (C,D) by SY, and $(\mathbf{E}, \mathbf{F})$ by $Y S$.

patches if the founders and later arrivers come from the same genetically heterogeneous source or if the founders and later arrivers come from genetically different sources. Nonetheless, even if simultaneous colonizers are genotypically heterogenous, kin individuals are more likely to interact with each other than with non-kin, at least until their density gets too high. The reason is that females deposit and aggregate their eggs at their feeding sites, which inevitably results in local kin subgroups within larger groups/colonies/patches. Whether it is single, several, or many individuals colonizing the same plant or site on a plant is tightly linked to the mode of dispersal and spinning thread-following behaviors, as described below.

\section{Species and Behavioral-Ecological Contexts}

We restrict our perspective of spider mite cooperation to species of two widely studied genera, that is, Tetranychus and the nest-building grass mite Stigmaeopsis (syn. Schizotetranychus), and consider interactions among kin, non-kin, conspecific, and heterospecific spider mites (Figure 1). The contexts looked at from a cooperation perspective comprise host plant colonization and exploitation, web-sharing for anti-predator benefits, and dispersal by Tetranychus spp., and nesting-associated behaviors by Stigmaeopsis spp. infesting bamboo and other grasses. Each behavioral-ecological context is illustrated by examples from the literature. We describe the current state of knowledge of behavioral characteristics and proximate aspects, and we contemplate and discuss whether the described behaviors have evolved for direct and/or indirect fitness benefits, which subtype of cooperation they seem to represent, and whether they require a given degree of genetic relatedness to enhance the fitness of both actors and recipients.

\section{HOST PLANT COLONIZATION AND EXPLOITATION BY TETRANYCHUS SPP.}

Depending on the mode of dispersal (Sabelis and Dicke, 1985 for an overview), i.e., whether by ambulation or by roping from exploited host plants or passively via the air and wind currents (either alone or collective; dubbed ballooning when mediated by the use of spinning threads, Bell et al., 2005), spider mites may colonize a new host plant either solitarily or as a collective. Collective ballooning is characterized by mites aggregating on the apex of leaves or plants, forming balls by joint webbing, and being carried away by the wind (e.g., Clotuche et al., 2011). Solitary ballooning has been reported in other spider mite genera (e.g., Fleschner et al., 1956), but in Tetranychus spp., ballooning usually represents collective behavior. Dispersal by roping and ambulation are basically and initially solitary behaviors, but if spinning threads are followed by others, they become collective.

On the host plants, spider mite females create local patches by ovipositing at feeding sites, but they also actively aggregate. Active aggregation may be proximately brought about by following the threads of other individuals (Yano, 2008; Astudillo Fernandez et al., 2012a), attraction to webbed areas 
(e.g., Clotuche et al., 2012, 2013a), and/or attraction to local changes in host plant chemistry (Kant et al., 2008; Rioja et al., 2017 for review). Also, visual and/or olfactory cues other than those present on the web, such as odor, shape, and/or color of other individuals or the host plant surface, may play a role. The ultimate reason why spider mites aggregate is that they benefit in fitness from other individuals and their webs and other microhabitat modifications in terms of egg production (Oku et al., 2009; Le Goff et al., 2010) and survival (Le Goff et al., 2010; Yano, 2012). Allee effects (Allee, 1931; Stephens et al., 1999) are a major driving force, i.e., benefits accrued by the presence of conspecifics in the immediate surrounding more than outweigh the costs of competition. Up to a threshold in abundance, individual fitness and group size are positively correlated. Accordingly, grouped spider mites commonly reach higher fitness than solitary spider mites if the environment (the accessible leaf area) is adjusted for exploitation competition (Le Goff et al., 2010). Positive group effects are byproducts of cooperation (or synergism sensu Queller, 1985) and provide direct fitness benefits regardless of intra-group genetic relatedness. Indirect fitness benefits play also a role in joint host plant exploitation and grouping because of founder effects, and females depositing and aggregating their eggs at local feeding sites, often result in patches where kin are more likely to interact with each other than with non-kin. Overall, these benefits commonly outweigh the costs of group-living such as intensified local and regional competition for shared resources, particularly food and mates.

Proximately, enhanced direct fitness by grouping may be brought about by reducing the intensity of individual web production (thinner, shorter, and/or fewer threads; Hazan et al., 1974) when others contribute to the shared web, and local (same leaf) and/or regional (systemic, on other leaves) favorable modification of plant biochemistry, such as breaking down the plant defense system resulting in more favorable nutritional quality of the shared host plant (Kant et al., 2008; Rioja et al., 2017), and/or more favorable leaf morphology (Oku and Yano, 2007). The energy saved in web production can be invested in reproduction (Le Goff et al., 2010). Joining existing webs and choosing between webs are not always necessarily in favor of kin-produced webs (Le Goff et al., 2012), which points at direct fitness benefits (byproduct cooperation) being the primary drivers of such behaviors. Tetranychus spp. has been suggested to possess kin discrimination abilities in activities such as spatial distribution (Le Goff et al., 2009), dispersal (Bitume et al., 2013), and mate choice (Schausberger and Sato, 2020). Experimental evidence suggests that Tetranychus urticae can also discriminate in site choice between grouplabeled kin individuals from their own population (following inbreeding) and individuals from other populations and/or their products/environmental modifications and choose microhabitats that are most favorable, whether created by kin or not (Le Goff et al., 2012; Schausberger et al., 2019). When joining others on the same leaf or plant, later arrivers/followers, initially, recipients (either on the same leaf or other leaves of the same plant if systemic downregulation of plant defense has occurred) will benefit from pioneering colonizers who are initially the actors. Pioneers are later paid back by being released from costly individual web production and other aggregationrelated benefits such as enhanced mating opportunities and enhanced protection from predators (see also the section on web sharing under predation risk), and other abiotic and biotic hazards for themselves and their offspring. Joining other groups and tightening the levels of aggregation enhance the chances of survival under predation risk because of attack abatement, even when the webbing is light or absent (Dittmann and Schausberger, 2017). An intriguing example of non-kin interactions comes from Schausberger et al. (2019), who showed that individuals of one population heavily benefited (without any direct interactions) from microhabitat manipulation by webbing or host plant biochemistry by pioneering colonizers from another population ( $Y$ coming to $G$ environment), whereas in the reverse sequence, later arrivers were negatively affected ( $G$ coming to $\mathrm{Y}$ environment). This was possibly mediated by G- but not Y-individuals harboring endosymbiotic bacteria Cardinium, indicating that endosymbiotic bacteria may influence kin/nonkin cooperation in spider mites (Schausberger et al., 2019). In the sequence $Y$ coming to $G$, pioneers may be paid back and benefit from later arrivers/followers because of a larger gene pool (G-Y mating is more favorable in terms of egg production than G-G mating). Therefore, in the sequence G coming to $Y$, Gs were initially actors and Ys were recipients; after arrival, Ys became actors by fertilizing Gs to the benefit of Gs (Ys paid costs because $\mathrm{Y}$ males prefer fertilizing $\mathrm{G}$ females).

Another possible benefit of joining others and aggregation may be broadening of local gene pools, allowing for the mixing of genotypes by mites following the spinning threads of, and joining, non-kin individuals. This would be considered an indirect genetic effect (IGE; Wolf et al., 1998; Santostefano et al., 2017) and may be beneficial, among others, because spider mites suffer from inbreeding depression (Vala et al., 2003; Le Goff et al., 2009; Yoshioka and Yano, 2014; Schausberger et al., 2019). IGEs could be one possible reason why females from a more prolific T. urticae line performed worse when mixed in a group with females from a less prolific line in the experiments by Le Goff et al. (2014). Whether and how pioneering colonizers of host plants and later arriving spider mites could benefit from IGEs affecting cooperation in exploiting host plants is little explored. Mites indirectly changing each other's behaviors via IGEs would be seen as byproduct cooperation but could also be a mix between direct byproduct benefits and indirect kin-selected benefits (Alemu et al., 2014).

Whether joining others is also beneficial for heterospecific spider mites may depend on the density and response of residents to later arrivers. For example, Sarmento et al. (2011) showed that $T$. urticae may benefit from the downregulation of plant defense by pioneering plant colonizers Tetranychus evansi (T. evansi helped T. urticae as a by-product because T. urticae produced more eggs when following $T$. evansi) but when the local abundance of T. evansi becomes too high, T. urticae is adversely affected by the dense webs produced by $T$. evansi, which may even lead to local exclusion and extinction of $T$. urticae. Possibly, such an interspecific interaction may be better dubbed facilitation, in addition to or instead of cooperation; facilitation 
between different herbivorous mite species has also been shown by Glas et al. (2014) and has been reviewed by Blaazer et al. (2018). The interspecific interaction reported by Sarmento et al. (2011) is not to be seen as cooperative if it is just T. urticae who benefits; however, it may be that $T$. evansi receives some other, hitherto unknown, initial benefit from the arrival/presence of T. urticae. Similarly, Godinho et al. (2016) showed for T. evansi and T. ludeni that plants previously infested with either con- or heterospecific individuals promoted later arrivers and boosted their fitness (higher egg production on previously infested plants) because of the downregulation of plant defense by pioneering individuals.

\section{WEB SHARING AS AN ANTI-PREDATOR STRATEGY IN TETRANYCHUS SPP.}

As outlined in the section on host plant colonization and exploitation, Tetranychus spp. females readily join webs established by others (Yano, 2008; Clotuche et al., 2013a) because of positive group (Allee) effects (Yano, 2008; Astudillo Fernandez et al., 2012a; Clotuche et al., 2013a). In addition, joining Tetranychus spp. females that would otherwise have to construct a new web alone gain direct web-mediated benefits of immediate protection against generalist predatory mites that have difficulties in coping with profuse spider mite webs (Yano, 2012). Such web-mediated protection confers considerable survival benefits because the vast majority of predatory mites are diet generalists (McMurtry et al., 1970; Sabelis and Bakker, 1992; Yano, 2012; Otsuki and Yano, 2014). Furthermore, the risk of predation of resident Tetranychus spp. females that built the webs are not increased by joiners, and at low densities, there are no negative host plant-mediated group effects (Yano, 2012). This indicates that the direct costs of sharing fresh webs are low or negligible. Altogether, considerable direct fitness benefits and low costs to resident females promote web sharing under predation risk, independent of kinship, and, thus, represent byproduct cooperation. This explanation is supported by the fact that heterospecific Tetranychus spp. females, such as T. urticae, Tetranychus kanzawai, and T. evansi, may share webs under predation risk in a similar way as conspecifics do (Yano, 2012; Sato et al., 2016). Tetranychus spp. females usually oviposit on the surface of leaf undersides. However, when they are threatened by specialist predatory mites that are well able to cope with webs (Sabelis and Bakker, 1992) and feed preferentially on spider mite eggs (Blackwood et al., 2001; Furuichi et al., 2005a), they disperse from invaded patches (Bernstein, 1984; Grostal and Dicke, 1999; Fernández-Ferrari and Schausberger, 2013; Hackl and Schausberger, 2014; Freinschlag and Schausberger, 2016; Otsuki and Yano, 2019) or oviposit on the webs instead (Oku and Yano, 2007; Lemos et al., 2010; Murase et al., 2017). For example, in environments with T. kanzawai eggs on and off the web, the predatory mite Neoseiulus womersleyi largely refrains from killing eggs on webs. Shifting oviposition toward webs is a type of maternal care that reduces offspring predation risk and thereby confers direct fitness benefits (Otsuki and Yano, 2017). Other ovipositing females benefit from existing webs under predation risk (byproduct cooperation). Under no or low predation risk, Tetranychus spp. females usually do not deposit eggs on webs away from the leaf surface, which points at fitness costs of oviposition on webs. Costs may include delayed and/or more complicated access to the leaf surface by hatching offspring and/or eggs on webs away from the leaf surface being more strongly exposed to abiotic hazards such as rain and wind (Okada and Yano, 2021).

\section{COLLECTIVE DISPERSAL BY TETRANYCHUS SPP.}

\section{Collective Ambulatory Dispersal by Following Spinning Threads}

Tetranychus spp. females disperse on and between leaves of their host plant primarily by walking (Brandenburg and Kennedy, 1982; Margolies and Kennedy, 1985). Ambulatory dispersing Tetranychus females often follow spinning threads, functioning as trails, left by preceding females. Follower females reinforce the trails with their own spinning threads, providing an opportunity for collective choice of dispersal direction (Yano, 2008). Although ambulatorily dispersing Tetranychus females do not consistently display collective choices of feeding and oviposition sites (Astudillo Fernandez et al., 2012b), collectively dispersing Tetranychus females may gain byproduct benefits from sharing webs at the new feeding site, while Tetranychus females not following trails become solitary founders of new colonies with initially high intra-colony relatedness (Yano, 2008). Local colonies founded by solitary females may later merge into extended high-density patches representing an ensemble of local kin patches. The reasons why such collective choices do not always occur are debated (Astudillo Fernandez et al., 2012b). Collective site choices in environments with specialist predatory mites that use spider mite threads for prey-searching are costly (Roda et al., 2001; Furuichi et al., 2005b; Shinmen et al., 2010). Therefore, whether collective dispersal is more advantageous than solitary dispersal is thought to depend on the strength of "positive group effects" in new habitats (Astudillo Fernandez et al., 2012a). Whether spinning thread-following behavior is influenced by genetic relatedness between pioneers and followers is unclear, but it is often kin individuals that disperse from the same patch. Bitume et al. (2013) showed that both increased local density and closer genetic relatedness increased the ambulatory dispersal distance of $T$. urticae. Since direct fitness benefits accrue anyway, indirect benefits arising from local kin neighborhoods may be considered jointly acting or secondary selective forces of thread-following behavior.

\section{Collective Aerial Dispersal by Ballooning}

Besides ambulatory dispersal, Tetranychus females also disperse aerially, either alone (Smitley and Kennedy, 1985; Margolies, 1987) or as part of a woven ball (dubbed ballooning; Bell et al., 2005), which may contain both adults and immatures. Ballooning mites can also be phoretic if the balls are carried away by other animals (Brandenburg and Kennedy, 1982; 
Clotuche et al., 2011, 2013b). For collective ballooning, mites start to move to the apex of leaves and plants, and others follow the spinning threads to jointly produce webbing and form balls on the apex. Depending on the delay between the initiation of ball formation and take-off and the size of the balls, all ballooning mites survive and are carried away, or early arrivers are trapped inside and die and only those joining the ball at a later time survive until being carried away by the wind. Collective dispersal via ballooning could represent cooperation based on the expression and recognition of green beard alleles that may indicate kinship or not. Clotuche et al. (2013b) observed that Tetranychus individuals did not discriminate and segregate with kin during ball formation; however, this may have been due to mixed rearing before the experiment, allowing familiarization among kin and non-kin. Also, these experiments do not rule out a possible role of kin selection, because on a local scale Tetranychus individuals live more likely with kin than non-kin and, thus, may not need to discriminate who initiated or joins in ball formation. If usually formed by kin, individuals initiating ball formation could be considered kin-selected true altruists (indirect fitness gain outweighing direct fitness loss; Kay et al., 2019) because those individuals (actors) may be enclosed and die inside the balls, but may gain indirect benefits by helping kin recipients to disperse (Clotuche et al., 2011). Whether mites dying inside balls sacrifice themselves to aid in ball formation or are trapped accidentally by other mites requires close scrutiny. In any case, dying inside the balls just occurs if there is a long delay between initiating ball formation and being carried away by the wind; if the take-off occurs soon after initiation of ball formation, there are no dead individuals inside the balls (Clotuche et al., 2013b). One likely selective force of collective ballooning may be immediately acting Allee effects on the new host plant (byproduct cooperation), i.e., collective colonization of a new host plant increasing individual fitness because of positive group effects (synergism sensu Queller, 1985) as compared to solitary colonization (Clotuche et al., 2013a,b). Cooperation in forming high density aggregations on tips of overexploited host plants may also counter dehydration (byproducts), as has been shown for the house dust mite Dermatophagoides farinae (Glass et al., 1997).

\section{COOPERATIVE BEHAVIORS OF GRASS SPIDER MITES, STIGMAEOPSIS SPP.}

Eusociality has not yet been observed in mites, but cooperative brood care and overlapping generations, which correspond to the intermediate subsociality II degree of sociality (following the "nest building" subsocial route to eusociality; Michener, 1969; Wilson, 1971), are present in group-living spider mites (Saito, 2010). While Tetranychus spp. are also considered subsocial, some Stigmaeopsis spp. show advanced social organization (Saito, 2010). The genus Stigmaeopsis comprises a number of species that infest leaves of bamboo and other grasses in Asia; some species have been unintentionally introduced and are now established in the Americas and Europe by the bamboo trade (Ostoja-Starzewski, 2000; Pratt and Croft, 2000; Kiss et al., 2017).
A remarkable feature of Stigmaeopsis spp. is the construction of tunnel-like nests by spinning threads along the veins and edges on the lower surface of leaves. The mites feed, develop, and reproduce inside the nests. Until two decades ago, the genus Stigmaeopsis was regarded as a single species, Schizotetranychus (syn. Stigmaeopsis) celarius Banks. However, recent studies found differences in the range of host plant species, nest and group sizes, and in cooperative behaviors, such as nest building, enlarging, and repairing, waste management, nest defense against predators, and male-male aggression, resulting in the description of 15 species (Saito et al., 2004, 2018, 2019). In the following, we highlight four aspects of cooperative behaviors in the genus Stigmaeopsis, that is, nest building, nest/brood defense, male-male aggression including fights for females, and social immunity.

\section{Cooperative Nest Building and Nest/Brood Defense}

Predation pressure is a strong selective force for the evolution of sociality (e.g., Wilson, 1971). Woven nests of Stigmaeopsis spp. provide some physical protection from predators. However, several predators, such as the predatory mite Typhlodromus bambusae, are able to intrude into the nests, especially through nest entrances. Stigmaeopsis spp. (Stigmaeopsis miscanthi, Stigmaeopsis sabelisi, Stigmaeopsis longus, Stigmaeopsis celarius, and Stigmaeopsis nanjingensis) that construct extended large nests show cooperative brood defense (counterattack) by males against intruders. Nests of $S$. miscanthi are sometimes only occupied by a single male and then the male and females jointly defend the nest (Saito, 1990). Nests of S. longus (Figure 1) are commonly inhabited by several males, which jointly defend the nests. Adult mites (biparental, i.e., both males and females, or just males) drive potential intruders away from nests by pursuit, jabbing, and beating, and, sometimes, even kill immature predators (Saito, 1986a,b; Yano et al., 2011; Saito and Zhang, 2017). The success rate of counterattack varies among species (Mori and Saito, 2005), and increases as the number of adult mites in a nest increases, i.e., the success of counter-attacks positively correlates with the size of nests (Saito, 1986a,b; Yano et al., 2011; Saito and Zhang, 2017). Such cooperative defense behaviors seem absent or less effective in species that construct separate small nests, such as S. takahashii and S. saharai (Mori and Saito, 2005). However, their nests are so small and the nest entrances are so narrow that predators are rarely able to intrude. As a consequence, the physical protection provided by the small nests is much higher than that of extended large nests (Mori and Saito, 2004). Moreover, separate scattered nests decrease the success of predators in detecting nests with live prey inside, because nests with sucked-out prey corpses can function as a trap for predators (Saito et al., 2008). Altogether, these studies suggest that differences in nest and group sizes in the genus Stigmaeopsis are associated with divergence in anti-predator strategies: cooperative defense by counterattacking predators in large groups and constructing smaller more protective nests in small groups. Counterattacks against potential intruders protect their own and the offspring of nestmates but incur the costs of 
being killed by predators. Therefore, nest size and cooperative defense are regarded as key traits in the evolution of grass spider mite sociality.

\section{Male-Male Aggression and Fight for Females}

The group of $S$. miscanthi species (S. miscanthi HG and ML forms, S. sabelisi, S. continentalis, and S. formosa) infests Miscanthus spp. grass, enlarges and extends their nests over time, and counterattacks predatory intruders (Saito et al., 2018, 2019; Sato et al., 2019). Adult males are not only aggressive against predators but also against conspecific males and may even kill each other to establish a harem (Saito, 1990). Stigmaeopsis longus (Figure 1) engage in precopulatory mate guarding without lethal fighting, whereas S. miscanthi males may fight to death inside nests when competing for females. However, the intensity of male-male aggression, quantified by the frequency of lethal male fights, varies among species and among populations in the S. miscanthi species group and seems to correlate with winter harshness (Saito, 1995; Saito and Sahara, 1999; Sato et al., 2013). Winter harshness can mediate average genetic relatedness among nestmates in the S. miscanthi species group because motherson mating during spring colony-establishment occurs more likely in colder than warmer regions (Saito, 1995; Sato et al., 2013). Therefore, kin selection is a plausible explanation of the geographic variation in male-male aggression. Non-lethal fighting may represent cooperation by non-killing actors helping kin recipients to survive and reproduce at the expense of a decrease in the direct fitness of the actor but an increase in indirect fitness (Saito, 1995; Saito and Mori, 2005). Alternatively, lethal fighting could represent spite (Hamilton, 1970; Foster et al., 2001; Gardner and West, 2006; Sato et al., 2013).

\section{Social Immunity: Cooperative Nest Sanitation and Waste Management}

Social immunity is defined as "any collective and personal mechanism that has emerged and/or is maintained at least partly due to the anti-parasite defense it provides to other group members" (Meunier, 2015). In nest-building organisms, social immunity is achieved by nest sanitation behaviors to prevent or reduce disease transmission and keep the living space inside nests clean. Waste management is widespread from communal to eusocial species (Jackson and Hart, 2009) and is closely associated with the evolution of sociality in the Acari (Saito, 1997). Some species of the genus Stigmaeopsis show obvious waste management (Figure 1). For example, the S. miscanthi HG form, which lives on Miscanthus spp. grass, constructs large woven nests by continuously extending its nests. In exceptional cases, large nests may be inhabited by more than a hundred individuals with three overlapping generations (Saito et al., 2000). Inside the nests, one or several fecal piles, spaced at similar distances, may be found. Fecal piles emerge by two simple behavioral rules: mites deposit their feces at sites with previous feces; in absence of previous feces, they deposit their feces inside the nest close to one of the two entrances (Sato et al., 2003). The mites recognize fecal sites by volatile chemical cues and the nest entrance by tactile cues
(Sato et al., 2003). Similar waste management has been observed in S. longus, which also constructs continuously enlarged nests but infests bamboo plants. However, in this species, the first fecal pile is deposited outside nests (Sato and Saito, 2006; Figure 1). Stigmaeopsis takahashii and S. saharai, which also infest bamboo plants but rather construct separate new nests than expand existing nests, deposit their feces outside the nest entrances, and do not respond to volatile chemical cues (Sato and Saito, 2006, 2008). Therefore, the use of volatile chemical cues in waste management is thought to have co-evolved with extending and enlarging existing nests. In S. longus, additional highly sophisticated nest cleaning behaviors have been reported. Females keep spinning threads after nest construction, which not only function to reinforce the nests but also to remove exuviae and other dust, possibly containing pathogens, scattered on the leaf surface inside nests (Kanazawa et al., 2011). To this end, females walk in a zigzag pattern and spin threads that are soft and sticky when fresh. These threads trap the exuviae and dust from the floor (the leaf surface) of the nests. Females push the trapped exuviae and dust up and glue them to the woven roof of the nest, resulting in a clean leaf surface inside the nests beneath the roof. Cooperation in nest building and social immunity activities have clear direct benefits, so arise from byproducts, but it is more than plausible to also assume a role of kin selection in these behaviors and indirect fitness benefits since it is usually and predominantly kin that live together and enlarge nests (kin fidelity sensu Sachs et al., 2004).

\section{CONCLUSION}

For most behavioral contexts looked at, cooperation by spider mites is based on shared interests between partners, that is, byproduct cooperation. In interactions such as host plant exploitation, collective dispersal, and shared nests, closer than average genetic relatedness is a likely consequence of host plant colonization and settling processes inevitably resulting in more frequent and more likely encounters between kin than non-kin. Thus, partners may additionally benefit from close genetic relatedness to additionally obtain indirect fitness gains. Whether these cooperative behaviors have evolved because of close kinship or are more likely to occur among kin than nonkin is a readily testable hypothesis if requiring kin discrimination, but is more difficult to test if they are due to founder effects and/or population viscosity (here, individuals do not have to actively recognize kin to more likely interact with kin than nonkin). However, because Tetranychus spider mites commonly live in high-density patches, it is very unlikely that they evolved fine-scale kin discrimination abilities, such as among siblings, aunts, and nieces, but group-level discrimination abilities, such as among populations, subpopulations, and lines, are obviously present (Le Goff et al., 2009, 2014; Schausberger et al., 2019; Schausberger and Sato, 2020).

Highly important aspects to consider in future studies that address the question of whether cooperative behaviors of spider mites evolved for direct and/or indirect fitness benefits are the origin, sampling, and rearing history, and with that the 
level of relatedness and familiarity, of the individuals used for experimentation. Considering the high intrinsic rates of increase of spider mites and patchy distribution, laboratory populations founded by specimens sampled in the wild from only one site or plant may present little genetic variation. Moreover, spider mites commonly have long been reared in the laboratory before being subjected to experiments and may, thus, represent inbred (sub)-populations or lines with close average inter-individual relatedness. Also, joint vs. separate rearing is an issue if grouplevel kin recognition is brought about by shared local or regional features of the environment (such as a shared host plant) serving for environmentally acquired population or line-specific labels. Thus, studies are prone to fail in establishing sufficient genetic or environmentally acquired variation between kin and non-kin or among differing degrees of kinship if just using individuals of one and the same inbred population for cooperation, kin recognition, and other topically pertinent studies.

Overall, our brief reports of selected behavioral-ecological contexts, considerations, thoughts, and views of cooperation and behaviors akin to cooperation in spider mites emphasize the great potential and experimental suitability of these animals for addressing fundamental questions in the cooperation framework. This perspective article may serve as a base and starting point to stimulate, guide, and/or intensify research on this exciting topic using spider mites as highly rewarding model animals.

\section{REFERENCES}

Alemu, S. W., Berg, P., Janss, L., and Bijma, P. (2014). Indirect genetic effects and kin recognition: estimating IGEs when interactions differ between kin and strangers. Heredity 112, 197-206. doi: 10.1038/hdy.2013.92

Allee, W. C. (1931). Animal aggregations, a study in general sociology. Chicago: University of Chicago Press.

Astudillo Fernandez, A., Hance, T., Clotuche, G., Mailleux, A.-C., and Deneubourg, J. L. (2012a). Testing for collective choices in the two-spotted spider mite. Exp. Appl. Acarol. 58, 11-22. doi: 10.1007/s10493-012-9558-5

Astudillo Fernandez, A., Hance, T., and Deneubourg, J. L. (2012b). Interplay between Allee effects and collective movement in metapopulations. Oikos 121, 813-822. doi: 10.1111/j.1600-0706.2011.20181.x

Azandémè-Hounmalon, G. Y., Fellous, S., Kreiter, S., Fiaboe, K. K. M., Subramanian, S., Kungu, M., et al. (2014). Dispersal behavior of Tetranychu sevansi and T. urticae on tomato at several spatial scales and densities: implications for integrated pest management. PLoS One 9:e95071. doi: 10.1371/journal.pone.0095071

Bell, J. R., Bohan, D. A., Shaw, E. M., and Weyman, G. S. (2005). Ballooning dispersal using silk: world fauna, phylogenies, genetics and models. Bull. Entomol. Res. 95, 69-114. doi: 10.1079/ber2004350

Bernstein, C. (1984). Prey and predator emigration responses in the acarine system Tetranychus urticae-Phytoseiulus persimilis. Oecologia 61, 134-142. doi: 10. 1007/BF00379099

Bitume, E. V., Bonte, D., Ronce, O., Bach, F., Flaven, E., Olivieri, I., et al. (2013). Density and genetic relatedness increase dispersal distance in a subsocial organism. Ecol. Lett. 16, 430-437. doi: 10.1111/ele.12057

Blaazer, C. J. H., Villacis-Perez, E. A., Chafi, R., Van Leeuwen, T., Kant, M. R., and Schimmel, B. C. J. (2018). Why do herbivorous spider mites suppress plant defenses? Front. Plant Sci. 9:1057. doi: 10.3389/fpls.2018.01057

Blackwood, J. S., Schausberger, P., and Croft, B. A. (2001). Prey-stage preference in generalist and specialist phytoseiid mites (Acari: Phytoseiidae) when offered Tetranychus urticae (Acari: Tetranychidae) eggs and larvae. Environ. Entomol. 30, 1103-1111.

Brandenburg, R. L., and Kennedy, G. G. (1982). Intercrop relationships and spider mite dispersal in a corn/peanut agro-ecosystem. Entomol. Exp. Appl. 32, 269-276. doi: 10.1111/j.1570-7458.1982.tb03217.x

\section{DATA AVAILABILITY STATEMENT}

The original contributions presented in the study are included in the article/supplementary material, further inquiries can be directed to the corresponding author/s.

\section{AUTHOR CONTRIBUTIONS}

PS conceived the study idea and coordinated the writing. PS, SY, and YS wrote the original draft of the manuscript and contributed to manuscript revisions. All authors contributed to the article and approved the submitted version.

\section{FUNDING}

Open access funding was provided by the University of Vienna.

\section{ACKNOWLEDGMENTS}

PS thanks the topic editors for the invitation to contribute an article to this research topic.

Clotuche, G., Deneubourg, J.-L., Mailleux, A.-C., Detrain, C., and Hance, T. (2012). Discrimination through silk recognition: the case of the two-spotted spider mite Tetranychus urticae. C. R. Biol. 335, 535-540. doi: 10.1016/j.crvi.2012. 07.001

Clotuche, G., Mailleux, A.-C., Astudillo Fernandez, A., Deneubourg, J.-L., Detrain, C., and Hance, T. (2011). The formation of collective silk balls in the spider mite Tetranychus urticae Koch. PLoS One 6:e18854. doi: 10.1371/journal.pone. 0018854

Clotuche, G., Mailleux, A.-C., Yano, S., Detrain, C., Deneubourg, J.-L., and Hance, T. (2013a). Settlement decisions by the two-spotted spider mite Tetranychus urticae. C. R. Biol. 336, 93-101. doi: 10.1016/j.crvi.2013.02.006

Clotuche, G., Navajas, M., Mailleux, A.-C., and Hance, T. (2013b). Reaching the ball or missing the flight? Collective dispersal in the two-spotted spider mite Tetranychus urticae. PLoS One 8:e77573. doi: 10.1371/journal.pone.0077573

Dittmann, L., and Schausberger, P. (2017). Adaptive aggregation by spider mites under predation risk. Sci. R. 7:1. doi: 10.1038/s41598-017-10819-8

Fernández-Ferrari, M. C., and Schausberger, P. (2013). From repulsion to attraction: species- and spatial context-dependent threat sensitive response of the spider mite Tetranychus urticae to predatory mite cues. Naturwissenschaften 100, 541-549. doi: 10.1007/s00114-013-1050-5

Fleschner, C. A., Badgley, M. A., Rocker, D. W., and Hall, J. C. (1956). Air drift of spider mites. J. Econ. Entomol. 49, 624-627.

Foster, K. R., Wenseleers, T., and Ratnieks, F. L. W. (2001). Spite: Hamilton's unproven theory. Ann. Zool. Fennici 38, 229-238.

Freinschlag, J., and Schausberger, P. (2016). Predation risk-mediated maternal effects in the two-spotted spider mite, Tetranychus urticae. Exp. Appl. Acarol. 69, 35-47. doi: 10.1007/s10493-016-0014-9

Furuichi, H., Oku, K., Yano, S., Takafuji, A., and Osakabe, M. (2005a). Why does the predatory mite Neoseiulus womersleyi Schicha (Acari: Phytoseiidae) prefer spider mite eggs to adults? Appl. Entomol. Zool. 40, 675-678. doi: 10.1303/aez. 2005.675

Furuichi, H., Yano, S., Takafuji, A., and Osakabe, M. (2005b). Prey preference of the predatory mite Neoseiulus womersleyi Schicha is determined by spider mite webs. J. Appl. Entomol. 129, 336-339.

Gardner, A., Griffin, A. S., and West, S. A. (2009). "Theory of Cooperation," in Encyclopedia of Life Sciences (ELS), (Chichester: John Wiley \& Sons, Ltd).

Gardner, A., and West, S. A. (2006). Spite. Curr. Biol. 16:R662-R664. 
Glas, J. J., Alba, J. M., Simoni, S., Villarroel, C. A., Stoops, M., Schimmel, B. C. J., et al. (2014). Defense suppression benefits herbivores that have a monopoly on their feeding site but can backfire within natural communities. BMC Biol. 12:98. doi: 10.1186/s12915-014-0098-9

Glass, E. V., Yoder, J. A., and Needham, G. R. (1997). Clustering reduces water loss by adult American house dust mites Dermatophagoides farinae (Acari: Pyroglyphidae). Exp. Appl. Acarol. 22, 31-37. doi: 10.1007/s11118-011-9244-y

Godinho, D. P., Janssen, A., Dias, T., Cruz, C., and Magalhães, S. (2016). Downregulation of plant defence in a resident spider mite species and its effect upon con- and heterospecifics. Oecologia 180, 161-167. doi: 10.1007/s00442-0153434-z

Grostal, P., and Dicke, M. (1999). Direct and indirect cues of predation risk influence behavior and reproduction of prey: a case for acarine interactions. Behav. Ecol. 10, 422-427. doi: 10.1093/beheco/10.4.422

Hackl, T., and Schausberger, P. (2014). Learned predation risk management by spider mites. Front. Ecol. Evol. 2:58. doi: 10.3389/fevo.2014.00058

Hamilton, W. D. (1964). The genetical evolution of social behavior I \& II. J. Theor. Biol. 7, 1-52. doi: 10.1016/0022-5193(64)90038-4

Hamilton, W. D. (1970). Selfish and spiteful behaviour in an evolutionary model. Nature 228, 1218-1220. doi: 10.1038/2281218a0

Hazan, A., Gerson, U., and Tahori, A. S. (1974). Spider mite webbing I. - the production of webbing under various environmental conditions. Acarologia 16, 68-84.

Helle, W., and Sabelis, M. W. (1985). Spider mites. Their biology, natural enemies and control. Amsterdam: Elsevier.

Jackson, D. E., and Hart, A. G. (2009). Does sanitation facilitate sociality? Anim. Behav. 77, e1-e5.

Kanazawa, M., Sahara, K., and Saito, Y. (2011). Silk threads function as an 'adhesive cleaner' for nest space in a social spider mite. Proc. R. Soc. B Biol. Sci. 278, 1653-1660. doi: 10.1098/rspb.2010.1761

Kant, M. R., Sabelis, M. W., Haring, M. A., and Schuurink, R. C. (2008). Intraspecific variation in a generalist herbivore accounts for induction and impact of host-plant defenses. Proc. R. Soc. B Biol. Sci. 275, 443-452. doi: 10.1098/rspb.2007.1277

Kay, T., Lehmann, L., and Keller, L. (2019). Kin selection and altruism. Curr. Biol. 29, R438-R442.

Kiss, E., Szénási, Á, Neményi, A., and Kontschán, J. (2017). Can we use the predatory mites against the invasive bamboo pest spider mites? Acta Phytopathol. Entomol. Hung. 52, 91-96. doi: 10.1556/038.52.2017.014

Krainacker, D. A., and Carey, J. R. (1990). Ambulatory dispersal and life history response to food deprivation in two-spotted spider mites. Entomol. Exp. Appl. 56, 139-144. doi: 10.1111/j.1570-7458.1990.tb01391.x

Le Goff, G. J., Hance, T., Detrain, C., Deneubourg, J.-L., and Mailleux, A.-C. (2012). The locomotor activities on sites covered by silk produced by related and unrelated spider mites in Tetranychus urticae (Acari: Tetranychidae). C. R. Biol. 335, 226-231. doi: 10.1016/j.crvi.2012.02.002

Le Goff, G. J., Hance, T., Detrain, C., Deneubourg, J.-L., and Mailleux, A.-C. (2014). Impact of living with kin/non-kin on the life history traits of Tetranychus urticae (Acari: Tetranychidae). Exp. Appl. Acarol. 63, 37-47. doi: 10.1007/s10493-0149783-1

Le Goff, G. J., Mailleux, A.-C., Detrain, C., Deneubourg, J.-L., Clotuche, G., and Hance, T. (2009). Spatial distribution and inbreeding in Tetranychus urticae (Acari: Tetranychidae). C. R. Biol. 332, 927-933.

Le Goff, G. J., Mailleux, A.-C., Detrain, C., Deneubourg, J.-L., Clotuche, G., and Hance, T. (2010). Group effect on fertility, survival and silk production in the web spinner Tetranychus urticae (Acari: Tetranychidae) during colony foundation. Behaviour 147, 1169-1184. doi: 10.1163/000579510x510980

Lemos, F., Sarmento, R. A., Pallini, A., Dias, C. R., Sabelis, M. W., and Janssen, A. (2010). Spider mite web mediates anti-predator behaviour. Exp. Appl. Acarol. 52, 1-10. doi: 10.1007/s10493-010-9344-1

Li, J., and Margolies, D. C. (1993). Effects of mite age, mite density, and host quality on aerial dispersal behaviour in the two-spotted spider mite. Entomol. Exp. Appl. 68, 79-86. doi: 10.1111/j.1570-7458.1993.tb01691.x

Margolies, D. C. (1987). Conditions eliciting aerial dispersal behavior in banks grass mite, Oligonychus pratensis (Acari: Tetranychidae). Environ. Entomol. 16, 928-932. doi: 10.1093/ee/16.4.928

Margolies, D. C., and Kennedy, G. G. (1985). Movement of the two spotted spider mite, Tetranychus urticae, among hosts in a corn-peanut agroecosystem.
Entomol. Exp. Appl. 37, 55-61. doi: 10.1111/j.1570-7458.1985.tb03 452.x

McMurtry, J. A., Huffaker, C. B., and van de Vrie, M. (1970). Ecology of tetranychid mites and their natural enemies: a review. I. Tetranychid enemies: their biological characters and the impact of spray particles. Hilgardia 40, 331-390.

Meunier, J. (2015). Social immunity and the evolution of group living in insects. Philos. Trans. R. Soc. B Biol. Sci. 370:20140102. doi: 10.1098/rstb.2014.0102

Michener, C. D. (1969). Comparative social behavior of bees. Annu. Rev. Entomol. 14, 299-342.

Mori, K., and Saito, Y. (2004). Nest-size variation reflecting anti-predator strategies in social spider mites of Stigmaeopsis (Acari: Tetranychidae). Behav. Ecol. Sociobiol. 56, 201-206.

Mori, K., and Saito, Y. (2005). Variation in social behavior within a spider mite genus, Stigmaeopsis (Acari: Tetranychidae). Behav. Ecol. 16, 232-238. doi: 10.1093/beheco/arh157

Murase, A., Fujita, K., and Yano, S. (2017). Behavioural flexibility in spider mites: oviposition site shifts based on past and present stimuli from conspecifics and predators. R. Soc. Open Sci. 4:170328. doi: 10.1098/rsos.170328

Okada, S., and Yano, S. (2021). Oviposition-site shift in phytophagous mites reflects a trade-off between predator avoidance and rainstorm resistance. Biol. Lett. 17:20200669. doi: 10.1098/rsbl.2020.0669

Oku, K., Magalhães, S., and Dicke, M. (2009). The presence of webbing affects the oviposition rate of two-spotted spider mites, Tetranychus urticae (Acari: Tetranychidae). Exp. Appl. Acarol. 49, 167-172. doi: 10.1007/s10493-009-9 252-4

Oku, K., and Yano, S. (2007). Spider mites (Acari: Tetranychidae) deform their host plant leaves: an investigation from the viewpoint of predator avoidance. Ann. Entomol. Soc. Am. 100, 69-72.

Ostoja-Starzewski, J. (2000). Schizotetranychus celarius (Banks) (Acari: Prostigmata) a mite pest of bamboo; first records for Britain and two new host records. Br. J. Entomol. Nat. History 13, 95-97.

Otsuki, H., and Yano, S. (2014). Functionally different predators break down antipredator defenses of spider mites. Entomol. Exp. Appl. 151, 27-33. doi: 10.1111/eea.12164

Otsuki, H., and Yano, S. (2017). Within-patch oviposition site shifts by spider mites in response to prior predation risks decrease predator patch exploitation. Ethology 123, 453-459. doi: 10.1111/eth.12615

Otsuki, H., and Yano, S. (2019). The stealthiness of predatory mites as spider mite biological control agents. Biol. Control 136:104010.

Pratt, P. D., and Croft, B. A. (2000). Expanded distribution of the bamboo spider mite, Schizotetranychus longus (Acari: Tetranychidae), and predation by Neoseiulus fallacis (Acari: Phytoseiidae). Acarologia 40, 191-197.

Queller, D. C. (1985). Kinship, reciprocity and synergism in the evolution of social behavior. Nature 318, 366-367.

Queller, D. C. (2011). Expanded social fitness and Hamilton's rule for kin, kith, and kind. Proc. Natl. Acad. Sci. U. S. A. 108, 10792-10799. doi: 10.1073/pnas. 1100298108

Rioja, C., Zhurov, V., Bruinsma, K., Grbic, M., and Grbic, V. (2017). Plantherbivore interactions: a case of an extreme generalist, the two-spotted spidermite Tetranychus urticae. Mol. Plant Microbe Interact. 30, 935-945. doi: 10.1094/MPMI-07-17-0168-CR

Roda, A., Nyrop, J., English-Loeb, G., and Dicke, M. (2001). Leaf pubescence and two-spotted spider mite webbing influence phytoseiid behavior and population density. Oecologia 129, 551-560. doi: 10.1007/s004420100762

Sabelis, M. W., and Bakker, F. M. (1992). How predatory mites cope with the web of their tetranychid prey: a functional view on dorsal chaetotaxy in the Phytoseiidae. Exp. Appl. Acarol. 16, 203-225. doi: 10.1007/bf01193804

Sabelis, M. W., and Dicke, M. (1985). "Long-range dispersal and searching behaviour," in Spider Mites, Their Biology, Natural Enemies and Control, eds W. Helle and M. W. Sabelis (Amsterdam, The Netherlands: Elsevier Science), $141-160$.

Sachs, J. L., Müller, U. G., Wilcox, T. P., and Bull, J. J. (2004). The evolution of cooperation. Q. Rev. Biol. 79, 135-160.

Saito, Y. (1983). The concept of "life types" in Tetranychinae: an attempt to classify the spinning behaviour of Tetranychinae. Acarologia 24, 377-391.

Saito, Y. (1986a). Biparental defence in a spider mite (Acari: Tetranychidae) infesting Sasa bamboo. Behav. Ecol. Sociobiol. 18, 377-386. doi: 10.1007/ bf00299668 
Saito, Y. (1986b). Prey kills predator: counter-attack success of a spider mite against its specific phytoseiid predator. Exp. Appl. Acarol. 2, 47-62. doi: 10.1007/ bf01193354

Saito, Y. (1990). 'Harem' and 'non-harem' type mating systems in two species of subsocial spider mites (Acari, Tetranychidae). Popul. Ecol. 32, 263-278. doi: $10.1007 / \mathrm{bf} 02512562$

Saito, Y. (1995). Clinal variation in male-to-male antagonism and weaponry in a subsocial mite. Evolution 49, 413-417. doi: 10.1111/j.1558-5646.1995.tb02273.x

Saito, Y. (1997). "Sociality and kin selection in Acari," in The Evolution of Social Behaviour in Insects and Arachnids, eds J. C. Choe and B. J. Crespi (Cambridge: Cambridge University Press), 443-457.

Saito, Y. (2010). Plant Mites and Sociality. Diversity and Evolution. Tokyo: Springer.

Saito, Y., Chittenden, A. R., Mori, K., Ito, K., and Yamauchi, A. (2008). An overlooked side effect of nest-scattering behavior to decrease predation risk (Acari: Tetranychidae, Stigmaeidae). Behav. Ecol. Sociobiol. 63, 33-42. doi: 10.1007/s00265-008-0633-1

Saito, Y., and Mori, K. (2005). Where does male-to-male "aggression" compromise "cooperation"? Popul. Ecol. 47, 159-166.

Saito, Y., Mori, K., Chittenden, A. R., and Sato, Y. (2000). Correspondence of maleto-male aggression to spatial distribution of individuals in field populations of a subsocial spider mite. J. Ethol. 18, 79-83. doi: 10.1007/s101640070004

Saito, Y., Mori, K., Sakagami, T., and Lin, J. (2004). Reinstatement of the genus Stigmaeopsis Banks, with descriptions of two new species (Acari, Tetranychidae). Ann. Entomol. Soc. Am. 97, 635-646. doi: 10.1603/00138746(2004)097[0635:rotgsb]2.0.co;2

Saito, Y., and Sahara, K. (1999). Two clinal trends in male-male aggressiveness in a subsocial spider mite (Schizotetranychus miscanthi). Behav. Ecol. Sociobiol. 46, 25-29. doi: 10.1007/s002650050588

Saito, Y., Sato, Y., Chittenden, A. R., Lin, J.-Z., and Zhang, Y.-X. (2018). Description of two new species of Stigmaeopsis, Banks 1917 (Acari, Tetranychidae) inhabiting Miscanthus grasses (Poaceae). Acarologia 58, 414429. doi: 10.24349/acarologia/20184250

Saito, Y., Sato, Y., Kongchuensin, M., Chao, J.-T., and Sahara, K. (2019). New Stigmaeopsis species on Miscanthus grasses in Taiwan and Thailand (Acari, Tetranychidae). Syst. Appl. Acarol. 24, 675-682.

Saito, Y., and Zhang, Y. (2017). Locking out predators by silk, a new counterattack behaviour in a social spider mite. Ecol. Entomol. 42, 422-429. doi: 10.1111/een. 12402

Santostefano, F., Wilson, A. J., Niemelä, P. T., and Dingemanse, N. (2017). Indirect genetic effects: a key component of the genetic architecture of behavior. Sci. Rep. 7:10235. doi: 10.1038/s41598-017-08258-6

Sarmento, R. A., Lemos, F., Dias, C. R., Kikuchi, W. T., Rodrigues, J. C., Pallini, A., et al. (2011). A herbivorous mite down-regulates plant defence and produces web to exclude competitors. PLoS One 6:e23757. doi: 10.1371/journal.pone. 0023757

Sato, Y., Alba, J. M., Egas, M., and Sabelis, M. W. (2016). The role of web sharing, species recognition and host-plant defence in interspecific competition between two herbivorous mite species. Exp. Appl. Acarol. 70, 261-274. doi: 10.1007/ s10493-016-0079-5

Sato, Y., Egas, M., Sabelis, M. W., and Mochizuki, A. (2013). Male-male aggression peaks at intermediate relatedness in a social spider mite. Ecol. Evol. 3, 26612669. doi: 10.1002/ece3.661

Sato, Y., and Saito, Y. (2006). Nest sanitation in social spider mites: interspecific differences in defecation behavior. Ethology 112, 664-669. doi: 10.1111/j.14390310.2005.01184.x

Sato, Y., and Saito, Y. (2008). Evolutionary view of waste-management behavior using volatile chemical cues in social spider mites. J. Ethol. 26, 267-272. doi: 10.1007/s10164-007-0069-5
Sato, Y., Saito, Y., and Sakagami, T. (2003). Rules for nest sanitation in a social spider mite, Schizotetranychus miscanthi Saito (Acari: Tetranychidae). Ethology 109, 713-724.

Sato, Y., Tsuda, Y., Sakamoto, H., Egas, M., Gotoh, T., Saito, Y., et al. (2019). Phylogeography of lethal male fighting in a social spider mite. Ecol. Evol. 9, 1590-1602. doi: 10.1002/ece3.4770

Schausberger, P., Gotoh, T., and Sato, Y. (2019). Spider mite mothers adjust reproduction and sons' alternative reproductive tactics to immigrating alien conspecifics. R. Soc. Open Sci. 6:191201. doi: 10.1098/rsos.191201

Schausberger, P., and Sato, Y. (2020). Kin-mediated male choice and alternative reproductive tactics in spider mites. Biology 9:360. doi: 10.3390/biology9110360

Shinmen, T., Yano, S., and Osakabe, M. (2010). The predatory mite Neoseiulus womersleyi (Acari: Phytoseiidae) follows extracts of trails left by the two-spotted spider mite Tetranychus urticae (Acari: Tetranychidae). Exp. Appl. Acarol. 52, 111-118.

Smitley, D. R., and Kennedy, G. G. (1985). Photo-oriented aerial-dispersal behavior of Tetranychus urticae (Acari: Tetranychidae) enhances escape from the leaf surface. Ann. Entomol. Soc. Am. 78, 609-614.

Stephens, P. A., Sutherland, W. J., and Freckleton, R. P. (1999). What is the Allee effect? Oikos 87, 185-190.

Trivers, R. L. (1971). The evolution of reciprocal altruism. Q. Rev. Biol. 46, 35-57.

Vala, F., Breeuwer, J., and Sabelis, M. W. (2003). Sorting out the effects of Wolbachia, genotype and inbreeding on life-history traits of a spider mite. Exp. Appl. Acarol. 29, 253-264. doi: 10.1023/a:1025810414956

West, S. A., Griffin, A. S., and Gardner, A. (2007). Evolutionary Explanations for Cooperation. Curr. Biol. 17, R661-R672.

Wilson, E. O. (1971). Insect Societies. Cambridge, Mass: Harvard University Press.

Wolf, J. B., Brodie, E. D., Cheverud, J. M., Moore, A. J., and Wade, M. J. (1998). Evolutionary consequences of indirect genetic effects. Trends Ecol. Evol. 13, 64-69.

Yano, J., Saito, Y., Chittenden, A. R., and Sato, Y. (2011). Variation in counterattack effect against a phytoseiid predator between two forms of the social spider mite, Stigmaeopsis miscanthi. J. Ethol. 29, 337-342.

Yano, S. (2008). Collective and solitary behaviors of two-spotted spider mite (Acari: Tetranychidae) are induced by trail following. Ann. Entomol. Soc. Am. 101, 247-252. doi: 10.1603/0013-8746(2008)101[247:casbot]2.0.co;2

Yano, S. (2012). Cooperative web sharing against predators promotes group living in spider mites. Behav. Ecol. Sociobiol. 66, 845-853. doi: 10.1007/s00265-0121332-5

Yoshioka, T., and Yano, S. (2014). Do Tetranychus urticae males avoid mating with familiar females? J. Exp. Biol. 217, 2297-2300.

Conflict of Interest: The authors declare that the research was conducted in the absence of any commercial or financial relationships that could be construed as a potential conflict of interest.

Publisher's Note: All claims expressed in this article are solely those of the authors and do not necessarily represent those of their affiliated organizations, or those of the publisher, the editors and the reviewers. Any product that may be evaluated in this article, or claim that may be made by its manufacturer, is not guaranteed or endorsed by the publisher.

Copyright (c) 2021 Schausberger, Yano and Sato. This is an open-access article distributed under the terms of the Creative Commons Attribution License (CC BY). The use, distribution or reproduction in other forums is permitted, provided the original author(s) and the copyright owner(s) are credited and that the original publication in this journal is cited, in accordance with accepted academic practice. No use, distribution or reproduction is permitted which does not comply with these terms. 